
\title{
HRC seconcisp/OSS
}

\section{Melhorias de Processos com Foco}

na Redução de Infecção de Sítio

\section{Cirúrgico em Artroplastias}

\section{em um Hospital Público Secundário}

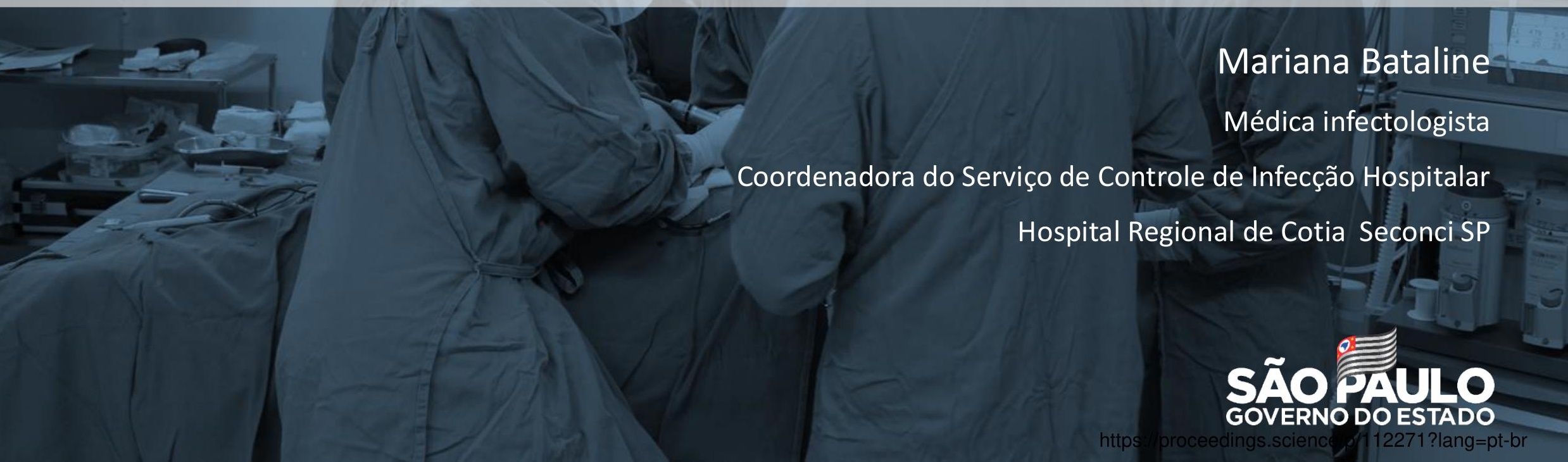




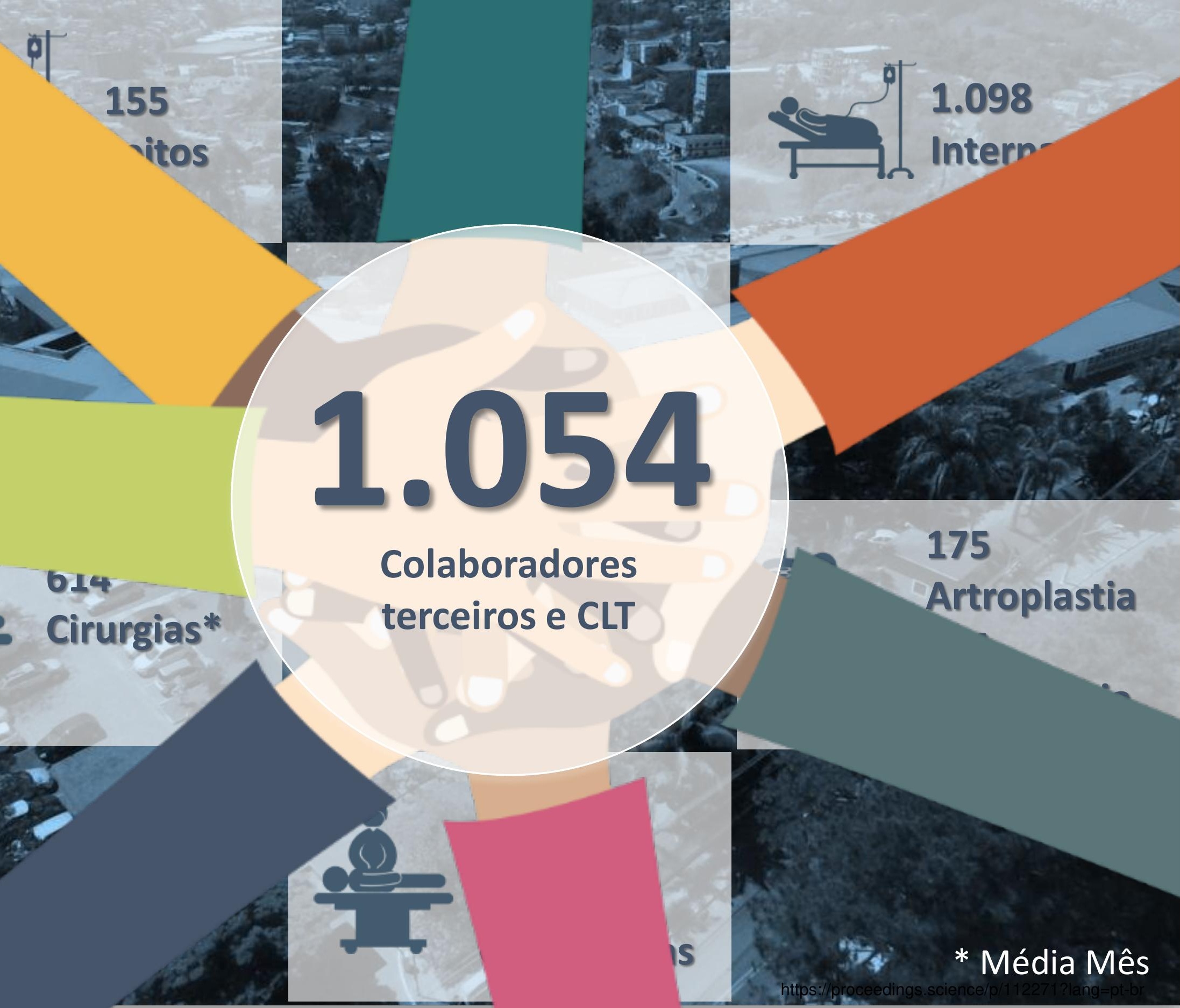




\section{Alívio de dor}

Atroplastias

Restabelecimento

de função 


\section{Infecções articulares periprotéticas}

Infecção de difícil tratamento

\section{Artrites}

Osteomielites

Toxicidade associada aos esquemas terapêuticos;

Re-intervenções cirúrgicas;

Dor e perda de função 


\section{PREVENCCÃO DEINFECÇÃO DE SÍTIO CIRURGICO}

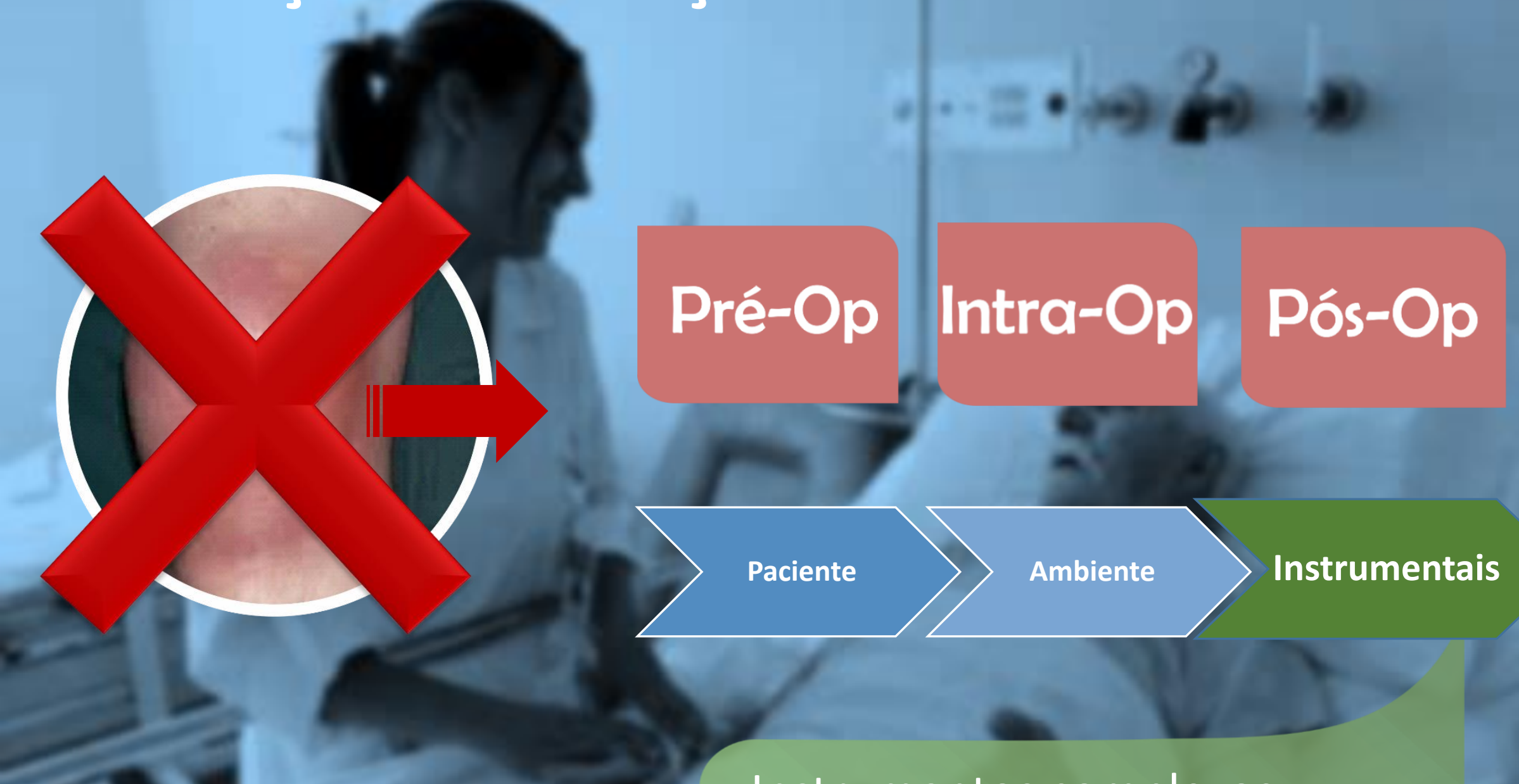

Instrumentos complexos

- Ranhuras

- Canulações

- Contato com medula óssea 


\section{Cenário 1}

ISC em artroplastias-2017

$\diamond$ Taxa joelho $\quad-T$-Taxa quadril $\triangle-$ Taxa geral

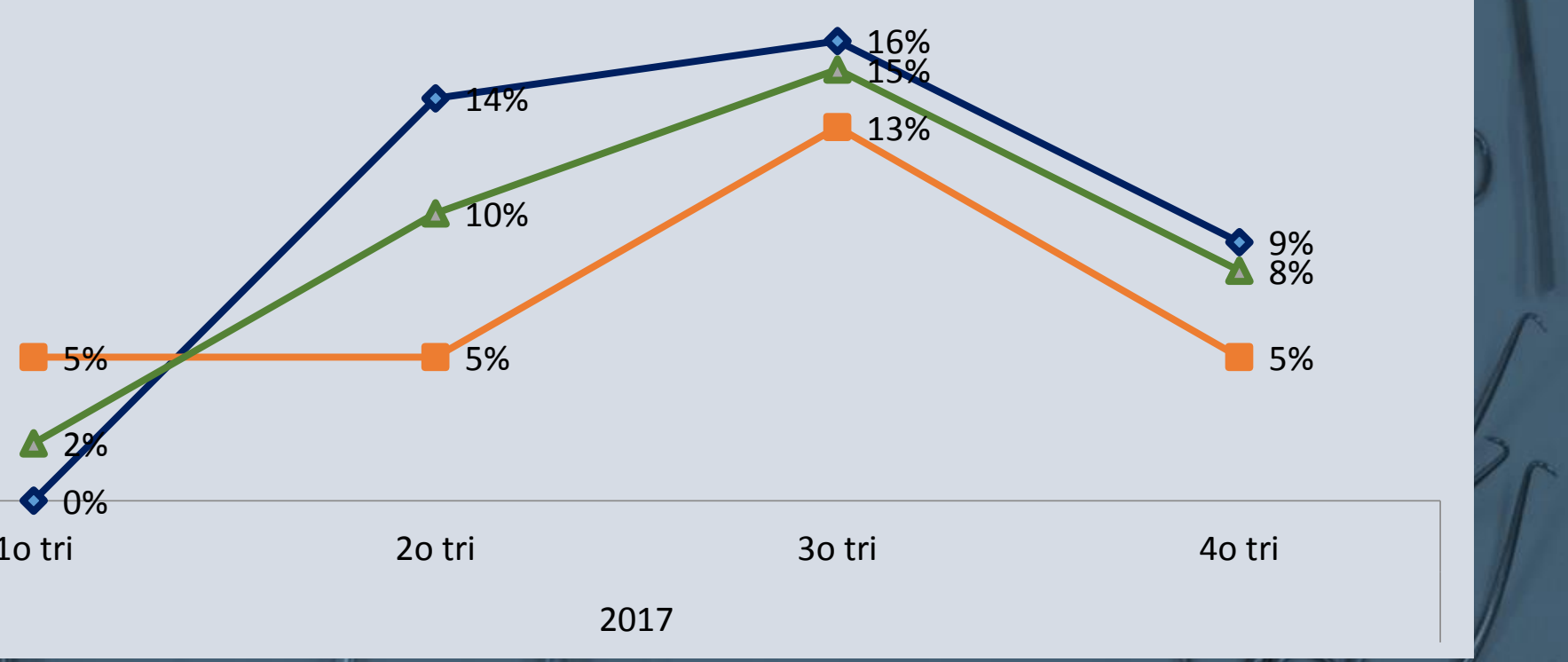

Taxa de IH anual=8,1\% 


\section{Análise do Problema}

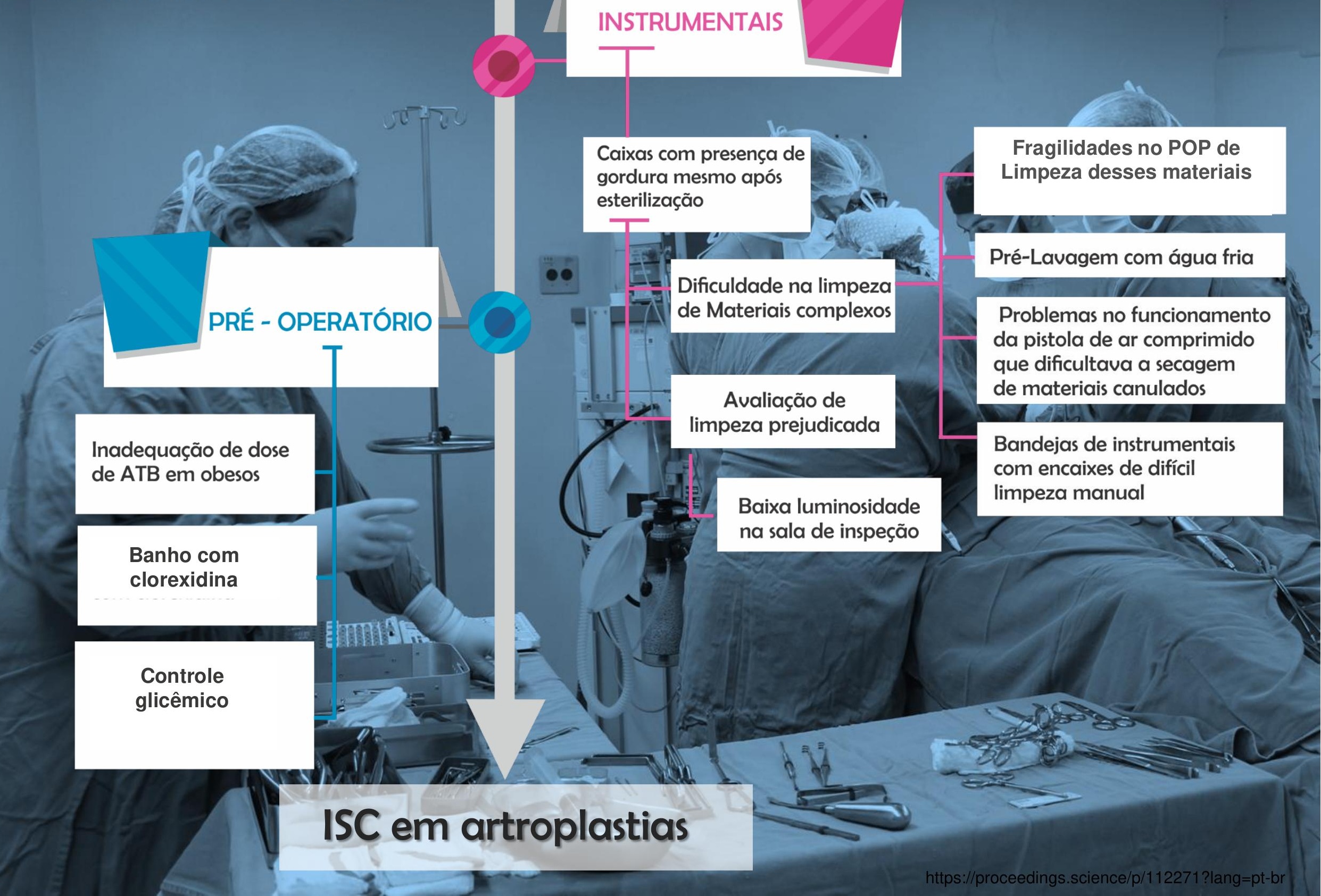


Adequação da

\section{Ações}

Revisão do Protocolo de limpeza e desinfecção com ajuste da troca do detergente enzimático após cada uso
Padronização do uso da lavadora ultrassônica para todos os instrumentais de artroplastias)

Adequação das

Reformulação da bandeja deinstrumentais em 5ro artroplastias (1)
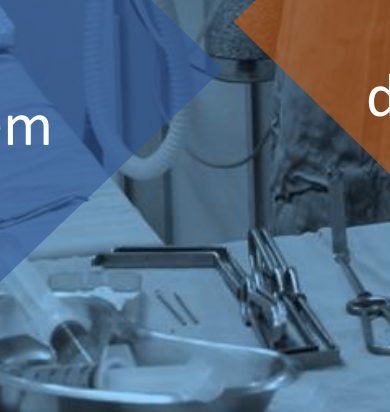
lentes de aumento e iluminação na área de inspeção visual da limpeza no CME Troca da pistola
Dupla checagem na inspeção visual dos instrumentais
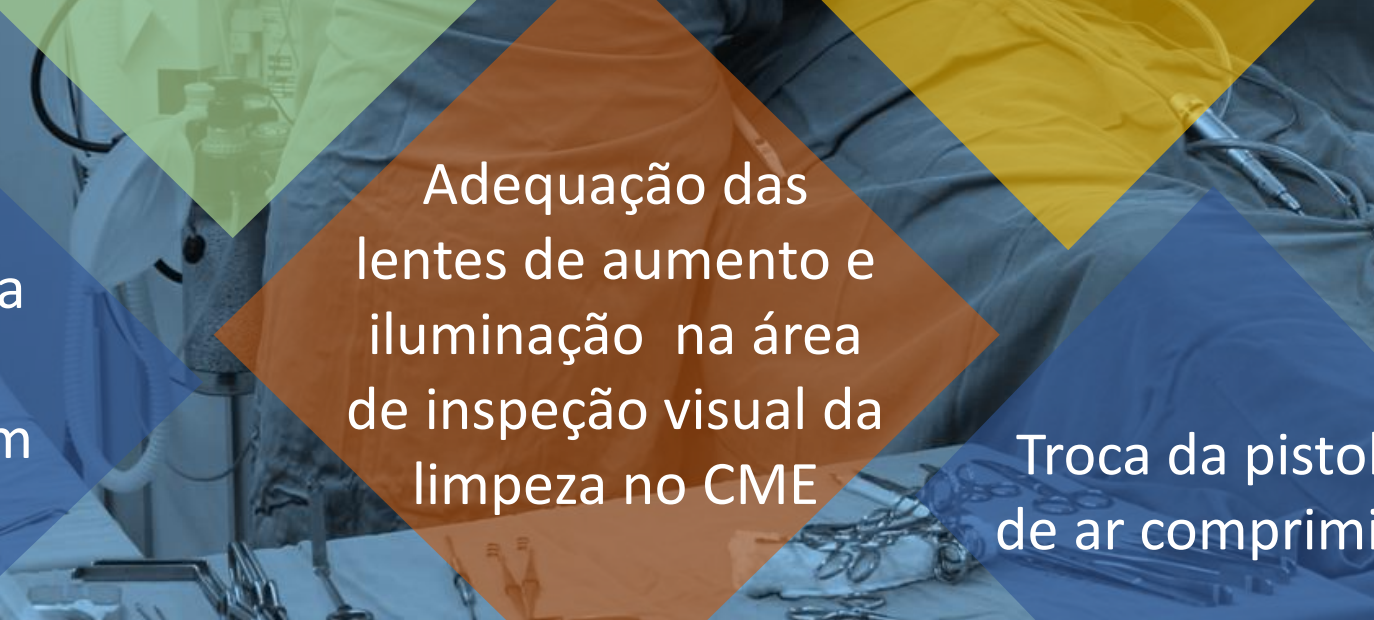
de ar comprimido 


\section{Verificação}

\section{ISC em artroplastias 2017-2018}

$\sim$ Taxa joelho - Taxa quadril $\_$Taxa geral

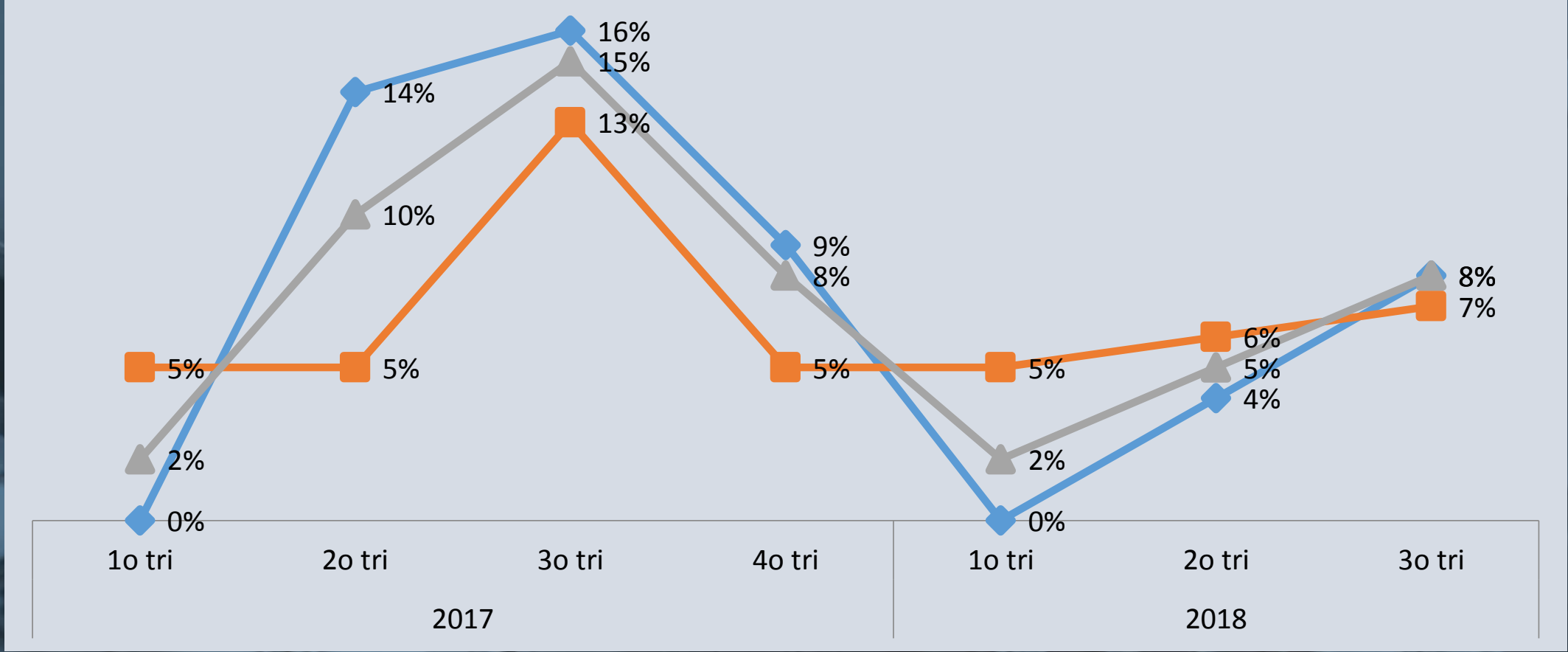




\section{Verificação}

\section{ISC em Artroplastias 2017-2018}

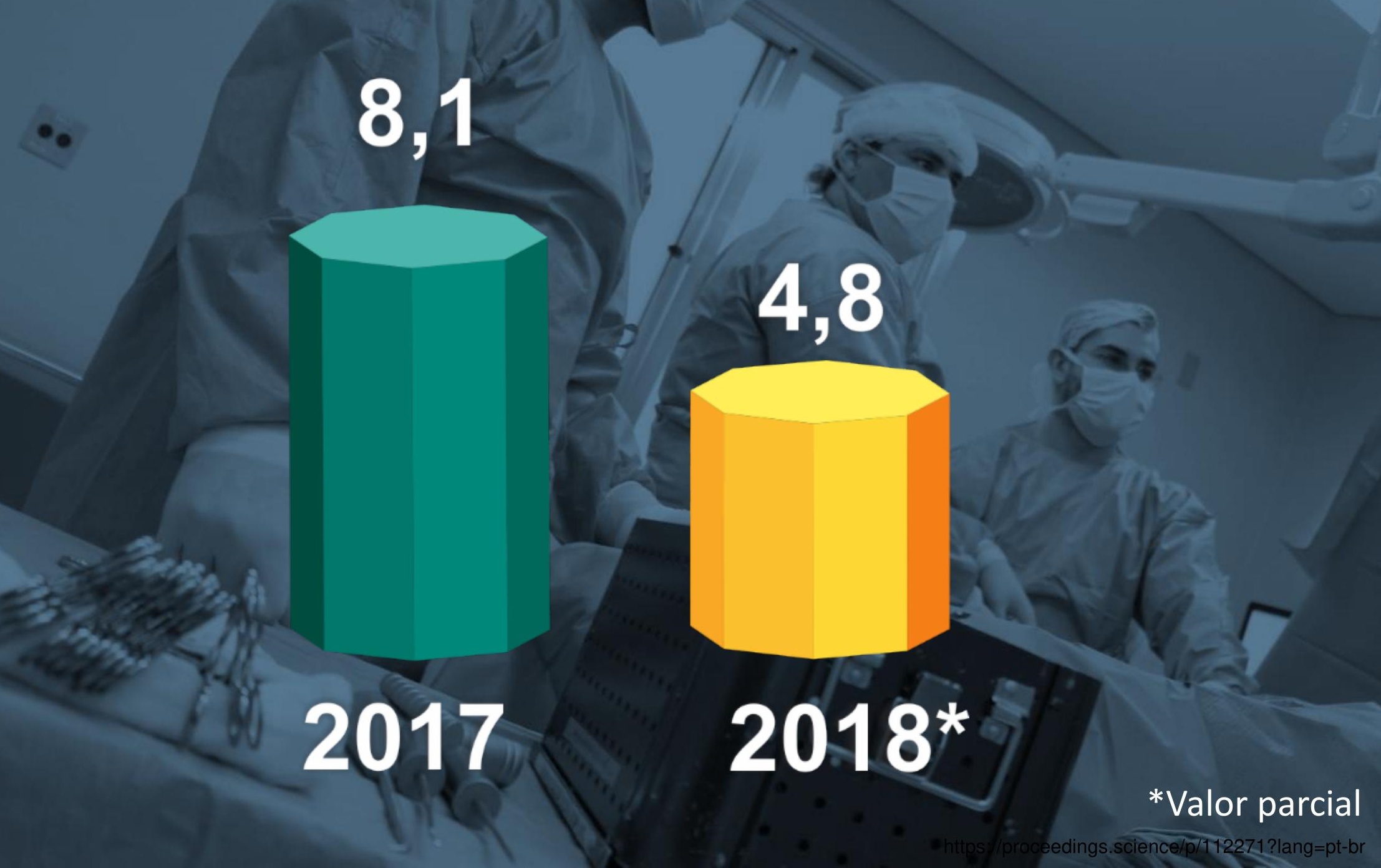




\section{Conclusão}

Para controle de Infecção de Sítio Cirúrgico em artroplastias é imprescindível, além de garantir medidas de prevenção focadas no paciente, ampliar o olhar de vigilância para melhorias nos processos de limpeza e esterilização de instrumentais

1.Artroplastia primária de joelho infectada: fatores de risco para falha na terapia cirúrgica. RBO. 2012; 2.Diretrizes Globais para a Prevenção de Infecções de Sítio Cirúrgico. ProQuali;

3.Epidemiologia da artroplastia total de quadril e de joelho: estudo transversal. Eintein. 2013; 4.APIC Implementation Guide: Infection Preventionist's Guide to the OR. 2018

O trabalho em equipe multidisciplinar e interssetorial é fundamental no controle de infecções relacionadas à assistência à saúde 


\section{HRC HRC seconcisp/OSS}

\section{OBRIGADA}

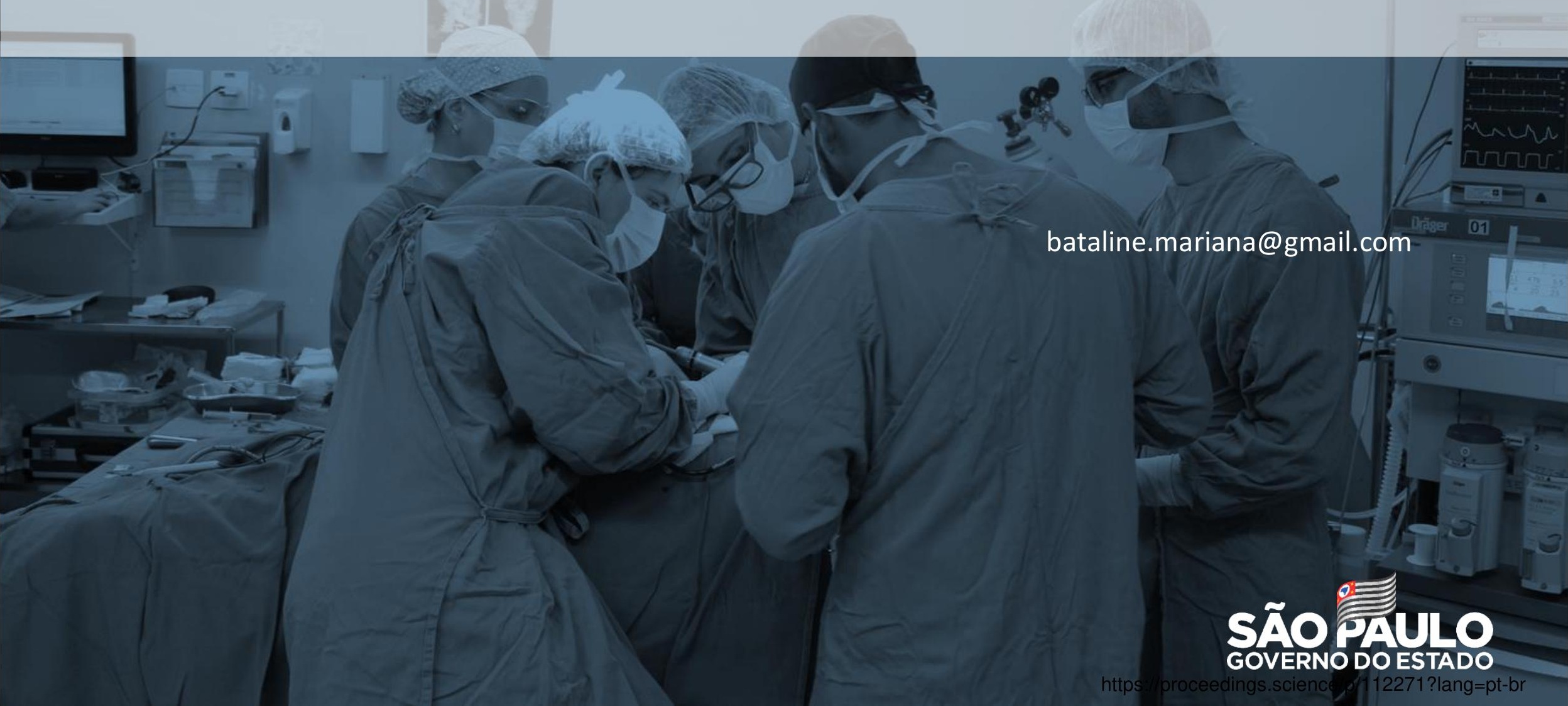

